\title{
QUANTITATIVE TEXTURE ANALYSIS OF AN ANORTHOSITE-APPLICATION TO THERMAL EXPANSION, YOUNG'S MODULUS AND THERMAL STRESSES
}

\author{
DAVID MAINPRICE and PHILIPPE MUNCH* \\ Laboratoire de Tectonophysique, Université de Montpellier II, 34095 Montpellier \\ Cedex, France. *Now at Laboratoire de Pétrologie Magmatique, Université \\ Aix-Marseille III St Jérôme, BP 411, 13397 Marseille Cedex 13, France
}

(Received 24 October 1990)

\begin{abstract}
Quantitative texture analysis of an anorthite (polycrystalline plagioclase feldspar) has been under taken using an optical microscope equipped with a universal stage. The microstructure was studied on three orthogonal sections. The microstructural shape analysis suggests an axial fabric which is confirmed by texture analysis. The texture has two major components, group I with $\perp(001)$ parallel to the axis of revolution and group II with $\perp(010)$. Group I has a much stronger axial character than group II. Using the orientation distribution function (ODF) defined by the individual orientations the thermal expansion, Young's Modulus and thermal stresses have been calculated for the plagioclase polycrystal. It is suggested that the distribution of thermal stresses could be used to estimate the orientation distribution of the poles to thermal cracks in the case of tensile (mode I) failure.
\end{abstract}

KEY WORDS Texture analysis, physical properties, minerals

\section{INTRODUCTION}

Texture analysis has been applied to many monomineralic rocks (see papers in Wenk, 1985). The majority of studies have been restricted to trigonal crystal symmetry (e.g. calcite and dolomite, Wenk, 1985; or quartz, Schmid and Casey, 1986) using X-ray texture goniometry. The application of neutron texture goniometry with a position sensitive detector to anorthosite (Wenk et al., 1986) has created new possibilities for the texture analysis of feldspar rocks. However, access to neutron diffraction facilities is extremely restricted, and the data processing is time consuming, hence such analysis is uncommon. Furthermore, no spherical harmonic programs currently exist to invert the neutron pole figure data to obtain the orientation distribution function (ODF) for triclinic crystal symmetry. Here we will present an alternative approach using the optical microscope equipped with a universal stage to measure individual grain orientations. The continuous ODF is not calculated, although in principle it is possible for individual orientation measurements (Bunge, 1982 p. 50, equation 4.20). Instead the function is represented by a series of contoured sections (e.g. Wenk and Wilde, 1972) and pole figures. The physical properties of the polycrystal (e.g. thermal expansion) may be calculated by summing the single crystal properties in the individual orientations. 


\section{PETROLOGY AND SPECIMEN STRUCTURE}

The rock specimen was taken from the Oman Ophiolite in the Sumail massif. The sample was structurally located a few hundred meters above the petrological Moho in the lower oceanic crust. The anorthosite formed a band about $20 \mathrm{~cm}$ thick in a layered gabbro sequence. The sequence has been interpreted as a fossil magma chamber at a mid-ocean ridge spreading centre (Nicolas et al., 1988).
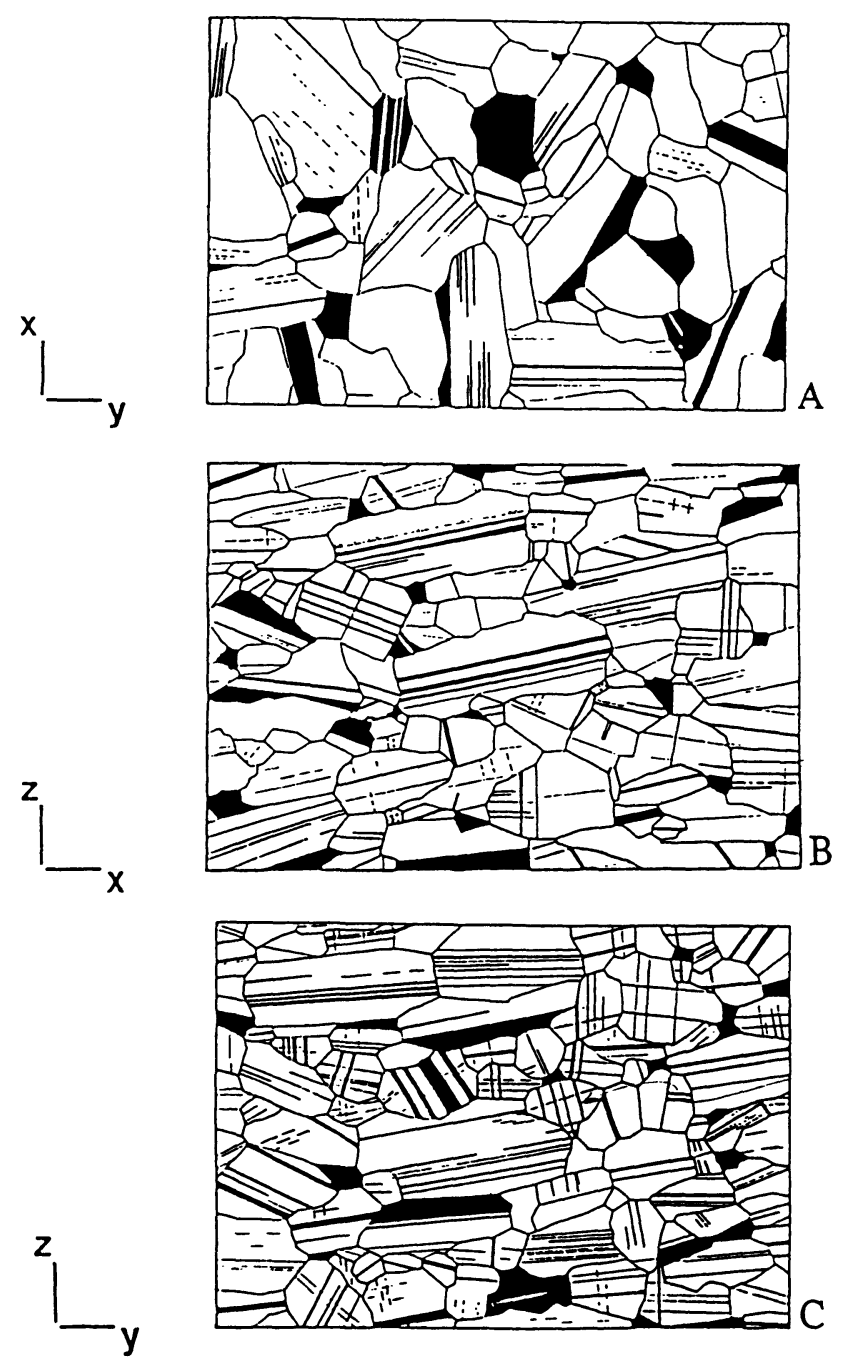

Figure 1 Microstructure in three perpendicular sections $\mathrm{XY}, \mathrm{XZ}$ and $\mathrm{YZ}$. Scale bar $1 \mathrm{~mm}$. 
The rock is composed entirely of plagioclase feldspar grains of $1 \mathrm{~mm}$ or less dimensions. The composition of the grains was determined by electron microprobe to be An $83 \pm 2$ and optical microscopy to be An $85 \pm 2$. The grain shape is euhedral to subeuhedral. Albite and pericline are the most frequently observed twins with subsidiary carlsbad twinning. In general, the twins are straight parallel sided and transect grains, some are seen to terminate at grain interiors. No optical undulose extinction or sub-grain structures have been observed.

A structural or specimen frame was defined by field observations in layered gabbro sequence. $X$ is defined by a mineral grain-shape lineation seen in the overlying gabbros and the XY plane is defined by the compositional banding (gabbro, anorthosite, gabbro). Three perpendicular thin-sections were cut in the $X Y, X Z$ and $Y Z$ orientations (Figure 1). In each section, the grain shape orientation was analysized using digitalized images and a microcomputer technique described by Allard and Benn (1989). The long and short axes and their orientation were recorded for each grain. A rose diagram of the orientation of the long axis of a large number of grains $(>200)$ for each section has been calculated. In the $\mathrm{XZ}$ and $\mathrm{YZ}$ a strong shape fabric is evident with many long axes aligned parallel to $X$ or $Y$. The strength of the shape fabric can be described by Rf, the ratio of the eigenvectors of the average shape ellipse (Harvey and Laxton, 1980), in the $\mathrm{XZ}$ and $\mathrm{YZ}$ sections $\mathrm{Rf}$ is 15.8 and 21.1 respectively. In contrast, in the $\mathrm{XY}$ section, the long axes are not highly aligned parallel to any particular direction, $\mathbf{R f}=\mathbf{0 . 9}$ close to the value for a circle $(\mathbf{R f}=\mathbf{1 . 0})$. A considerable number of long axes are aligned parallel to $X, Y$ and directions $45^{\circ}$ to these axes in the $X Y$ section. The grain shape analysis reveals a three dimensional axial symmetry with the sample $\mathrm{Z}$ axis being the axis of revolution.

\section{TWIN FREQUENCY}

When studying the texture of minerals it is often sufficient to determine the orientation of the optical indicatrix (e.g. olivine) or an optical axis and twin plane (e.g. calcite) in a single specimen section (e.g. XZ). In the case of triclinic minerals, such as plagioclase, the complete orientation can only be determined by the measurement of the optical indicatrix and two different crystallographic planes (cleavages or twins). In a given specimen section not all grains have two measurable cleavages or twins, hence a statistical description of the texture requires the study of three perpendicular sections (Kruhl, 1987) to take into account this sampling problem. In an optical microscope only planes at angles of less than $45^{\circ}$ to the microscope axis can be measured.

The starting point of any texture study of plagioclase is an estimate of the twin and cleavage frequency in each of the three perpendicular sections. In the present case only sections $\mathrm{YZ}$ and $\mathrm{XZ}$ had a significant number of grains with two crystallographic planes (54\% and $57 \%$ respectively) (Table 1). Hence, the YZ and $\mathrm{XZ}$ sections are the only sections where the classical measurement technique (Wenk et al., 1986) can be applied. It is important to note in the XY section $91 \%$ of the grains have only one measurable plane, whereas $35 \%$ and $37 \%$ of grains are in this category in the $\mathrm{YZ}$ and $\mathrm{XZ}$ sections. If it were possible to measure the 
Table 1 Twin frequency in the three orthogonal sections

\begin{tabular}{llcc}
\hline & $X Y$ & $Y Z$ & $X Z$ \\
\hline $\begin{array}{l}\text { grains with two twin planes, } \\
\text { albite and pericline }\end{array}$ & less than $1 \%$ & $54 \%$ & $57 \%$ \\
$\begin{array}{l}\text { grains with one twin plane } \\
\text { grains with no measureable } \\
\text { crystallographic plane }\end{array}$ & $91 \%$ & $35 \%$ & $37 \%$ \\
\hline
\end{tabular}

complete orientation from grains with one or more measurable planes then $91 \%$, $89 \%$ and $94 \%$ of grains could be measured in sections $\mathrm{XY}, \mathrm{YZ}$ and $\mathrm{XZ}$ respectively (see Seront $e t$ al., in press).

\section{MEASUREMENT TECHNIQUE}

The method of orientation measurement of plagioclase grains using a universal stage has been previously described by Wenk et al. (1986). The principal of the measurement is the simultaneous determination of the orientation of two crystallographic planes and the optical indicatrix, from these data a unique orientation and mineralogical composition are determined. We have undertaken these determinations on the $\mathrm{YZ}$ and $\mathrm{XZ}$ sections using an interactive computer program to perform the various rotations and data storage (Benn and Mainprice, 1989). The analysis was first performed on all the grains with two measurable planes, from these determinations the average plagioclase composition was determined to be An $85 \pm 2$.

\section{CRYSTALLOGRAPHIC FABRICS}

It is traditional in Earth Sciences to present the texture data in the form of specific pole figures. In the current example we have chosen to present the $\pm[100]$ axes and the poles to (010) and (001) as they correspond to orientations that can be directly measured. The (010) is the Albite twin plane and (001) is a common cleavage plane which has been measured in other samples by previous workers, and hence allows comparison with this study. The [100] direction is the intersection between the (010) and (001) planes, this direction must be within $45^{\circ}$ of the microscope axis when the measurements are made using the technique with two cleavages (e.g. Wenk et al., 1986).

When measuring the $\mathrm{YZ}$ section, the microscope axis is parallel to the $\mathrm{X}$ axis. The 96 measurements using two crystallographic planes (Albite and Pericline twin planes) must give a strong concentration of [100] axes parallel to the microscope (specimen X) axis (Figure 2). Similarly the geometrical constraints of the U-stage measurement require that the $(010)$ and $(001)$ poles lie on a great circle orientated parallel to the YZ section normal to the [100] axes maximum. The essential features revealed by this section are the strong concentration of the [100] axes in the XY plane and the concentrations of $\perp(010)$ and $\perp(001)$ parallel to the $\mathrm{Y}$ and $\mathrm{Z}$ axes. 


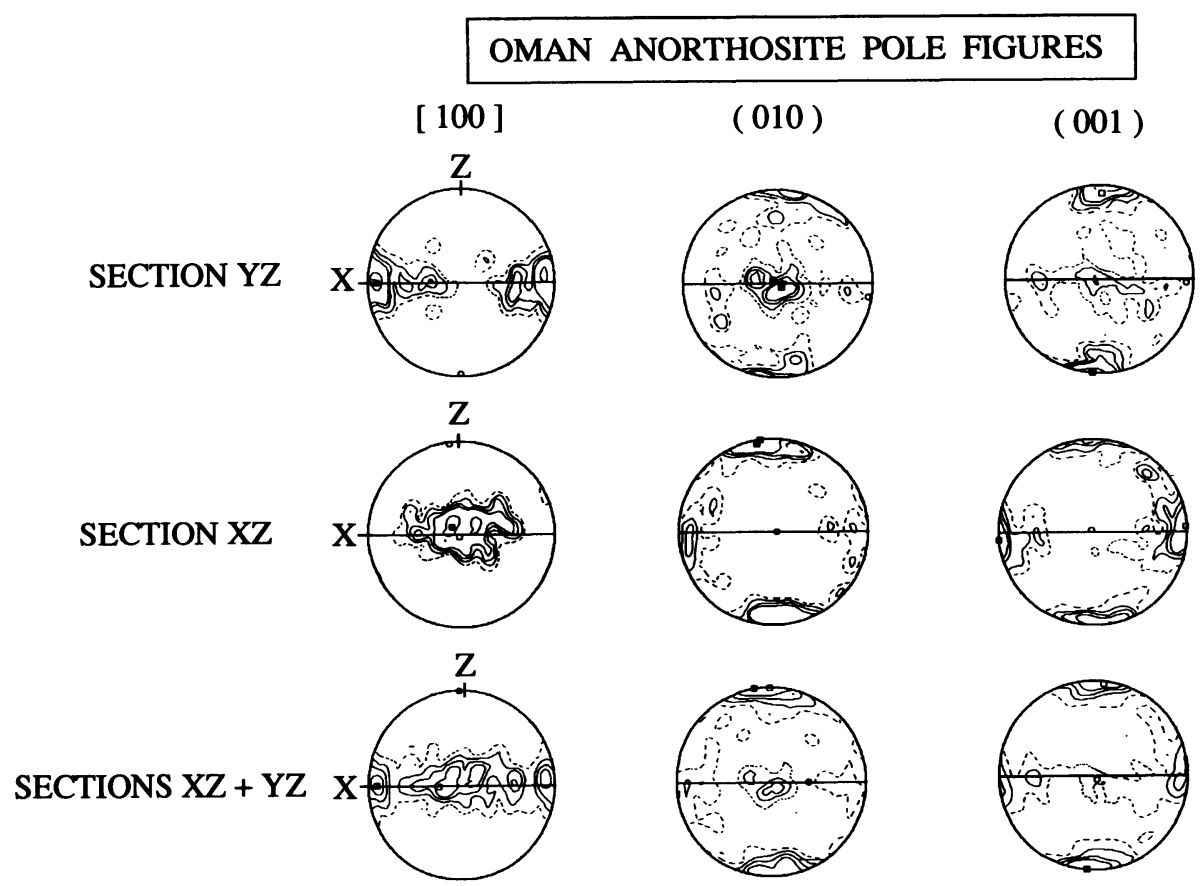

Figure $2 \pm[100], \perp(010)$ and $\perp(001)$ pole figures contoured in $1 \%$ counting area for measurements made on the $\mathrm{YZ}, \mathrm{XZ}$ and $\mathrm{XZ}+\mathrm{YZ}$ sections. Contours at $1,2,3$ and $4 \%$. The lowest contour is a dashed line. The solid black square is the maximum density. Number of measurements; $Y Z$ section 139, XZ section 138 and combined sections XY + YZ 277.

The $\mathrm{XZ}$ section reveals a similar situation with a strong concentration of [100] axes parallel to the microscope ( $Y$ specimen) axis and concentrations of $\perp(010)$ and $\perp(001)$ parallel to $Z$ and $X$ axes. The strong concentration of [100] is parallel to the $X Y$ plane as indicated by measurements in the $Y Z$ section.

The addition of $\mathrm{XZ}+\mathrm{YZ}$ sections reveal the total fabric with a strong concentration of [100] axes in the $X Y$ plane. The (010) poles have a strong concentration parallel to the $Z$ axis and a girdle in the $X Y$ plane, with a subsidiary concentration near $Y$ (Figure 2). The (001) poles form a strong concentration near the $Z$ axis and a girdle in the $X Y$ plane, with a subsidiary concentration near $X$. To verify the representivity of the measurements made on the $\mathrm{XZ}+\mathrm{YZ}$ sections, the orientation of horizontal poles of (010) in XY section (foliation plane) were calculated from these measurements and compared with independent measurements made with a flat-stage microscope on $X Y$ section. The U-stage measurements from the $X Z+Y Z$ sections and the flat-stage measurements from the $X Y$ section show the same angular distribution (Figure 3 ), indicating that the U-stage measurements give a good representation of the fabric. A more quantitative test of the representivity of texture measurements would require an independent measurement technique, such as neutron diffraction or electron channelling.

In the present analysis we have recorded the full orientation of the plagioclase grains, including the sign of the crystallographic axes. The axis distribution diagram of the $+[100]$ axes (Figure 4) shows the axes in the upper and lower 


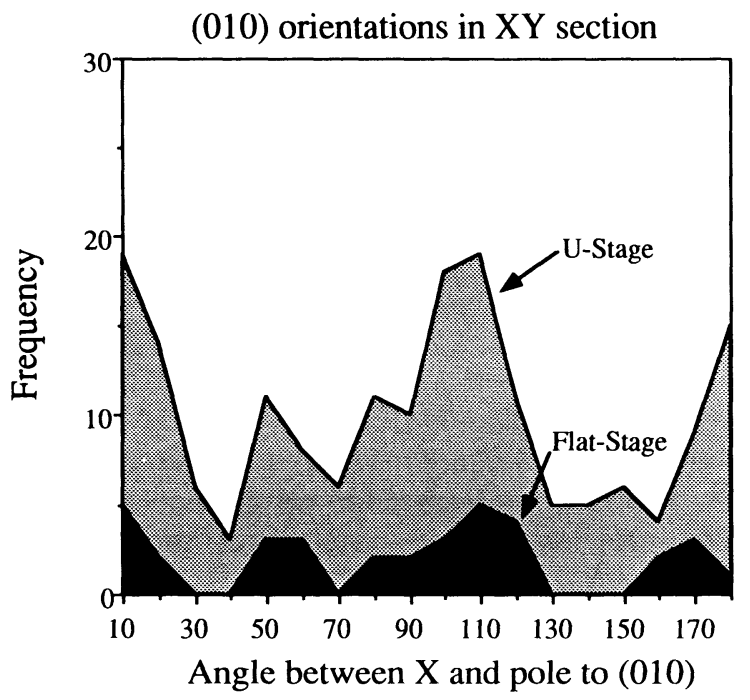

Figure 3 Frequency of $\perp(010)$ in the XY plane as a function of ange from $X$. The shaded area is from $U$-stage measurements in the $\mathrm{XZ}$ and $\mathrm{YZ}$ sections and the solid black area from flat stage measurements in the XY section.

hemisphere. No discernible difference could be seen between the distributions in each hemisphere.

\section{ORIENTATION DISTRIBUTION FUNCTION (ODF)}

The distribution of crystal orientations in specimen co-ordinates can be uniquely defined by the ODF (Bunge, 1982). The orientation of a crystal can be

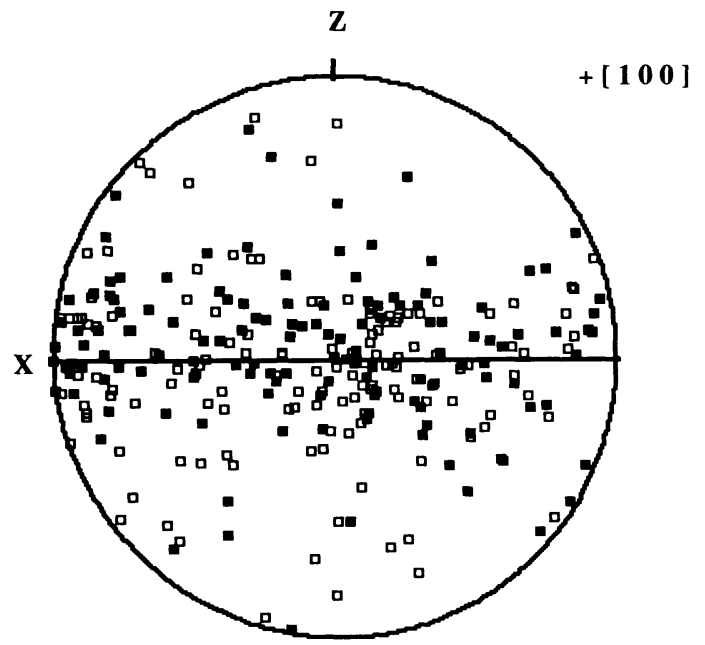

Figure $4 \pm[100]$ axes distribution diagram. The solid symbols represent axes in the upper hemisphere, and the hollow symbols represent axes in the lower hemisphere. 
conveniently defined by three Euler angles which describe the rotation of the crystal from some standard orientation in specimen co-ordinates to its actual orientation. To use the Euler description of rotation we need to define two right-handed orthogonal references axes, one in specimen co-ordinates and the other in crystal co-ordinates. The XYZ used in our microstructural description will be used as the specimen co-ordinate system. The [100], [010] and [001] axes in plagioclase are not orthogonal due to its triclinic crystal symmetry, here we have used [100], (001) pole and their cross-product as the orthogonal reference axes. Our choice was guided by the fact that this reference frame has also been used in the measurement of elastic constants in plagioclase (Alexandrov et al., 1974).

A method has been developed to calculate the ODF coefficients of the harmonic method from individual crystal (grain) orientations (Wagner et al., 1981). This technique is currently limited to crystals with at least one two-fold axis, hence cannot be applied to triclinic plagioclase. An alternative method representing the ODF either as a cloud of points in a three dimension space whose axes are the Euler angles or contoured sections through this discrete distribution (Wenk and Wilde, 1972) will be used in the present example.

\section{Oman Anorthosite ODF}

\section{Single grain orientations}

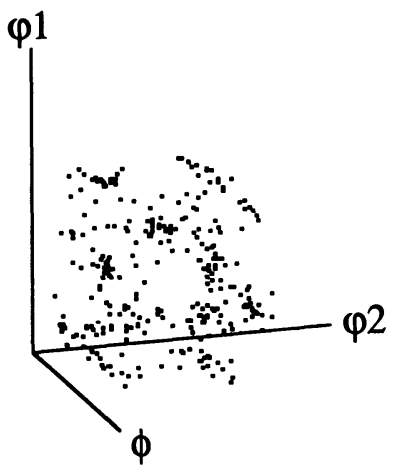

Skeleton pattern

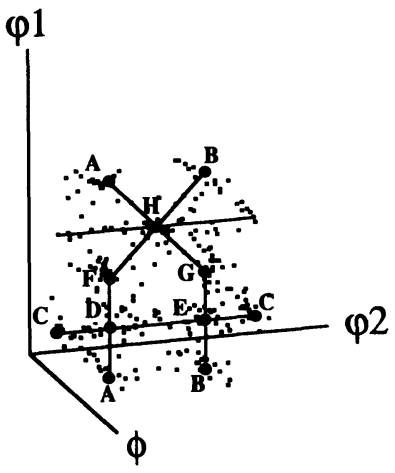

Figure 5 Representation of the ODF as discrete points for each of the 277 measured individual orientations. The major concentrations in the ODF are shown by the labelled skeleton lines. Letters correspond to the orientations given in Table 2 and the text. 
In the present case, triclinic specimen and crystal symmetry, the Euler space is limited to the ranges $\varphi_{1}=0-360, \phi=0-180$ and $\varphi_{2}=0-360$. In the Euler space a grain orientation can be represented by a point, resulting in a cloud of points for the 277 grains studied here (Figure 5). It is convenient to present the ODF as a series of contoured sections at constant $\varphi_{1}$ values. The contouring was done by dividing the Euler space into a series of counting volumes bounded by sides of $\Delta \varphi_{1} \Delta \phi \Delta \varphi_{2}$. The number of crystals contained in each box $\left(N_{i}\right)$ of volume $\left(\Delta V_{i}\right)$ was used to evaluate $f\left(g_{i}\right)$ as

$$
f\left(g_{i}\right)=\frac{N_{i}}{N \Delta V_{i}}=\frac{N_{i}}{N \sin \phi \Delta \varphi_{1} \Delta \phi \Delta \varphi_{2}}
$$

\section{Oman Anorthosite ODF sections}

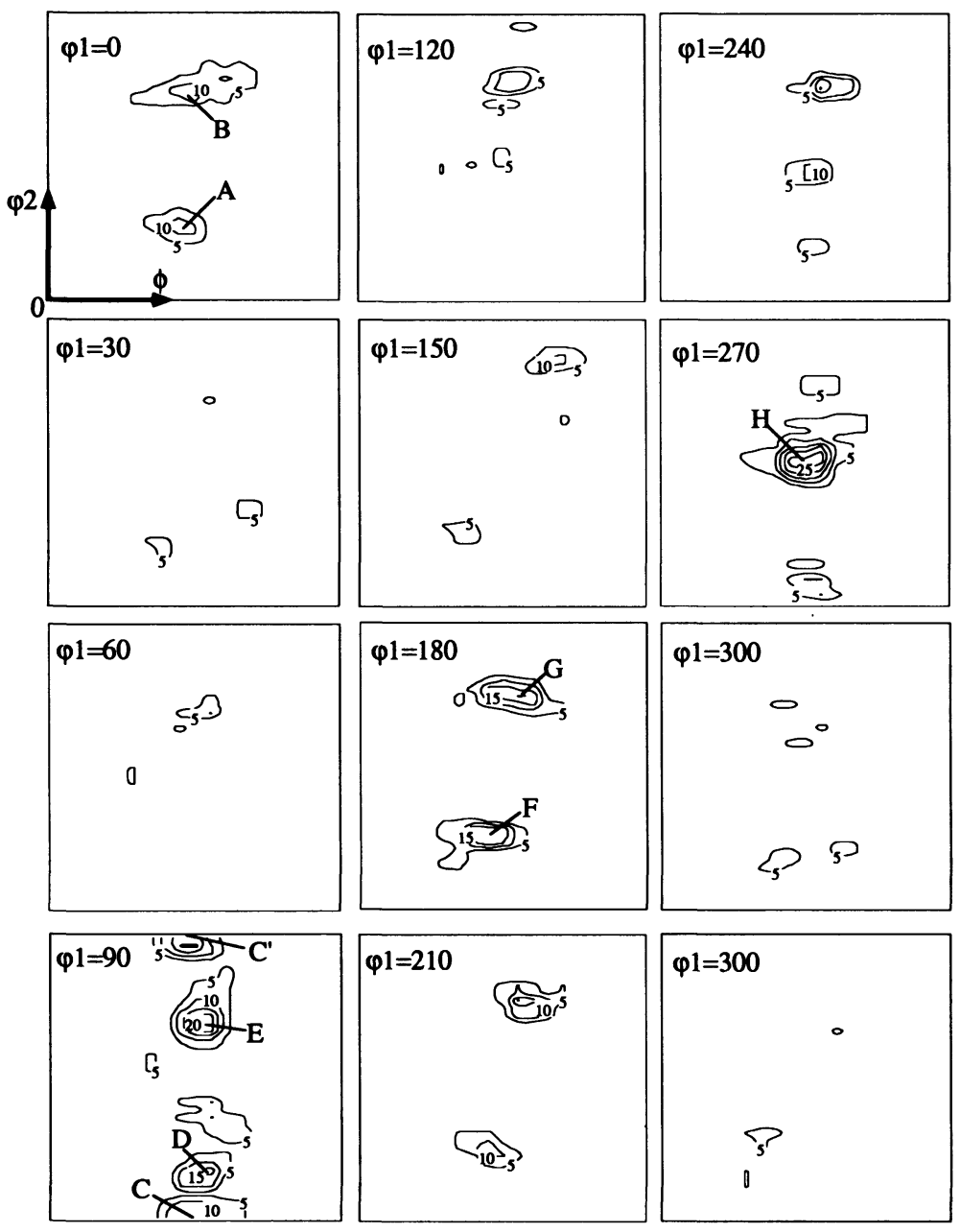

Figure 6 Sections of the ODF at constant $\varphi_{1}$ values. Contoured in multiples of a uniform distribution starting at 5 with an interval of 5 . Letters correspond to the orientations given in Table 2 and the text. 
Table 2 High density orientation in ODF

\begin{tabular}{llrrrll}
\hline Label & $f(g)$ & \multicolumn{1}{c}{$\varphi_{1}$} & \multicolumn{1}{c}{$\phi$} & \multicolumn{1}{c}{$\varphi_{2}$} & Description & Group \\
\hline A & 17 & 0 & 80 & 90 & {$[100] / / \mathrm{Y}$} & II \\
B & 17 & 0 & 90 & 270 & $\perp(001) / / \mathrm{X}$ & \\
C & 17 & 90 & 90 & 0 & & \\
D & 20 & 90 & 100 & 130 & {$[100]$ in XY plane } & I \\
E & 25 & 90 & 90 & 250 & & \\
C & 20 & 90 & 90 & 360 & $\perp(001) / / \mathrm{Z}$ & II \\
F & 25 & 180 & 70 & 90 & {$[100] / / \mathrm{Y}$} & \\
G & 25 & 180 & 100 & 270 & $\perp(001) / / \mathrm{X}$ & I \\
H & 35 & 270 & 90 & 180 & {$[100] / / \mathrm{X}$} & \\
& & & & & $\perp(001) / / \mathrm{Z}$ & II \\
A $^{\prime}$ & 35 & 360 & 80 & 90 & {$[100] / / \mathrm{Y}$} & \\
$\mathrm{B}^{\prime}$ & 12 & 360 & 90 & 270 & $\perp(001) / / \mathrm{X}$ & \\
\hline
\end{tabular}

given by Wenk et al. (1981). We have used a counting volume with sides $\Delta \varphi_{1}=\Delta \phi=\Delta \varphi_{2}=30^{\circ}$. The sin $\phi$ term in the volume element $\left(\Delta V_{i}\right)$ is required to give the correct counting metric for the Euler space.

The contoured sections at constant $\varphi_{1}$ values are presented in (Figure 6). With increasing $\varphi_{1}$ values we pass from two high densities of 17 times a uniform distribution at $\varphi_{1}=0$ to a high density $\operatorname{rod}(17-20-25-20)$ at $\varphi_{1}=90$. The rod structure breaks down to two high densities spots at $\varphi_{1}=180$. A similar bifurcated structure is found between $\varphi_{1}=180$ and $\varphi_{1}=360$, except that the structure at $\varphi_{1}=270$ shows a single maximum of 35 at $\phi=90 \varphi_{2}=180$ rather than the rod structure seen at $\varphi_{1}=90$. The asymmetry of the ODF about the $\varphi_{1}=180$ section (Figures 5 and 6) indicates that full triclinic crystal symmetry is necessary for the ODF, reflection symmetry about $\varphi_{1}=180$ would indicate that monoclinic crystal symmetry would be an adequate description. Eight different orientations can be recognized in the ODF (labelled $A$ to $\mathbf{H}$ in Figures 5 and 6; Table 2).

The eight orientations fall into two distinct groups, a first group (I) with $\varphi_{1}=90(\mathrm{C}, \mathrm{D}, \mathrm{E})$ or $\varphi_{1}=270(\mathrm{H})$ in which the $\perp(001)$ is parallel to $\mathrm{Z}$ and the [100] axes form a girdle in the XY plane; a second group (II) with $\varphi_{1}=0(\mathrm{~A}, \mathrm{~B})$, $\varphi_{1}=180(\mathrm{~F}, \mathrm{G})$ or $\varphi_{1}=360\left(\mathrm{~A}^{\prime}, \mathrm{B}^{\prime}\right)$ in which the $\perp(001)$ pole is parallel to $\mathrm{X}$ and [100] is parallel to $Z$. From this analysis it is clear that group $I$ forms an almost perfect axial symmetry pattern with the specimen $Z$ (or crystallographic (001) pole) as the symmetry axis, whereas group II has much weaker tendency towards an axial symmetry about $Z$ (or $(010)$ pole). The axial tendency of group $I$ is shown by the development of rods parallel to $\varphi_{2}$ axis (Figures 5 and 6).

\section{CALCULATED PHYSICAL PROPERTIES}

Once measured the ODF can be used for many applications apart from the study of orientation. Many physical properties can be calculated using the ODF if the appropriate single crystal properties are known. This is particularly useful in minerals which tend to have highly anisotropic physical properties. We will 
illustrate the calculation of physical properties using a second order (thermal expansion) and a fourth order property (Young's modulus).

The calculation procedure for second order properties is as follows;

a) the grain orientation (or rotation) matrix $\left(g_{i j}\right)$ is defined by the three Euler angles $\left(\varphi_{1} \phi \varphi_{2}\right)$

b) the single crystal tensor property $\left(T_{i j}\right)$ is rotated into the grain orientation using

$$
T_{i j}^{\prime}=g_{i k} \cdot g_{j l} \cdot T_{k l}
$$

c) the tensor property for each grain $\left(T_{i j}^{\prime}\right)$ are summed to give the aggregate property either using the Voigt average,

$$
\bar{T}_{i j}^{\text {Voigt }}=\frac{\sum_{1}^{N} T_{i j}^{\prime}}{N}
$$

or the Reuss average

$$
\bar{T}_{i j}^{\text {Reuss }}=\left[\frac{\sum_{1}^{N} T_{i j}^{\prime-1}}{N}\right]^{-1}
$$

d) The aggregate tensor property $T_{i j}$ can then be evaluated $(T)$ in any direction $\left(X_{i}\right)$ by

$$
T=T_{i j} \cdot X_{i} \cdot X_{j}
$$

An almost identical procedure can be used for tensorial properties of fourth order (e.g. Mainprice, 1990). The thermal expansion is a strain which is represented by second rank tensor. The coefficients of thermal expansion tensor $\alpha_{i j}$ depends on temperature. The principal thermal expansion coefficients $\left(\alpha_{11}, \alpha_{22}, \alpha_{33}\right)$ define the axial lengths of a representative quadric (ellipsoid or hyperboloid). In the case of a triclinic mineral the axes of the quadric are not parallel to low index crystallographic axes. For the composition of plagioclase the closest to our sample for which the coefficients have been determined (An 76, Crystal Bay, Minnesota) $\alpha_{11}=11 \times 10^{-6 \circ} \mathrm{C}^{-1}, \alpha_{22}=6 \times 10^{-60} \mathrm{C}^{-1}$ and $\alpha_{33}=-1 \times$ $10^{-6 \circ} \mathrm{C}^{-1}$ parallel to [833], [755] and [588] respectively (Williame et al., 1974) for the temperature range $25-600^{\circ} \mathrm{C}$. By calculating the angles between the principal thermal expansion directions and right-handed orthogonal Cartesian axes used for the ODF (defined by [100] and $\perp(001)$ ) we can transform the principal values to a thermal expansion tensor $\left(\alpha_{i j}\right)$ with same crystallographic reference axes as the ODF. The calculated thermal expansion stereogram (Figure 7) for the Oman polycrystal shows the expansion of greatest magnitude occurs near the XY plane with minimum near the $Z$ axis. The calculated thermal expansion anisotropy is in agreement with specimen microstructure which shows numerous cracks axial with the $\mathrm{Z}$ direction, possibly due to thermal cracking (cf. Fredrich and Wong, 1986).

The fourth rank tensor elastic properties have been calculated using a similar scheme to that above. Using the aggregate elastic constants the Young's modulus (E) has been calculated. The Young's modulus is given by reciprocal of the elastic stiffness $S_{1111}^{\prime}$ in direction $X_{i}$, which can be written in tensor notation as

$$
E=\frac{1}{S_{1111}^{\prime}}
$$




\section{THERMAL EXPANSION}

Single Crystal - An76

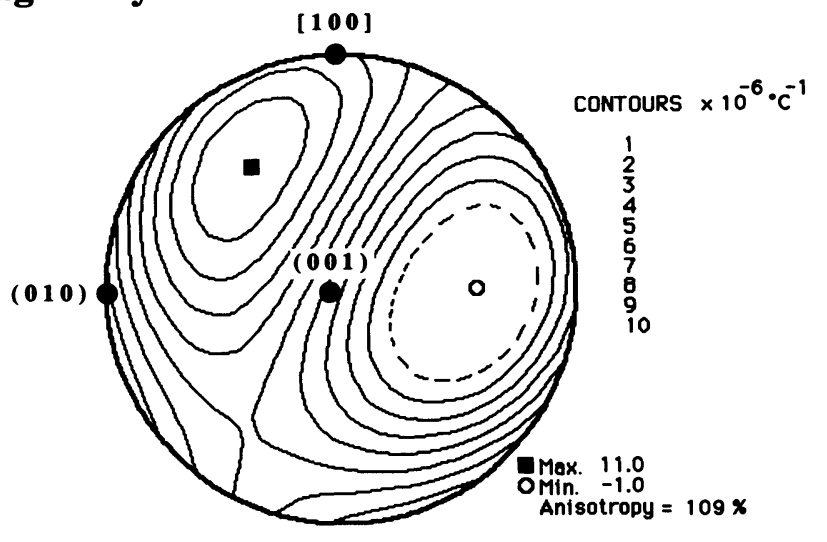

Oman - Polycrystal z

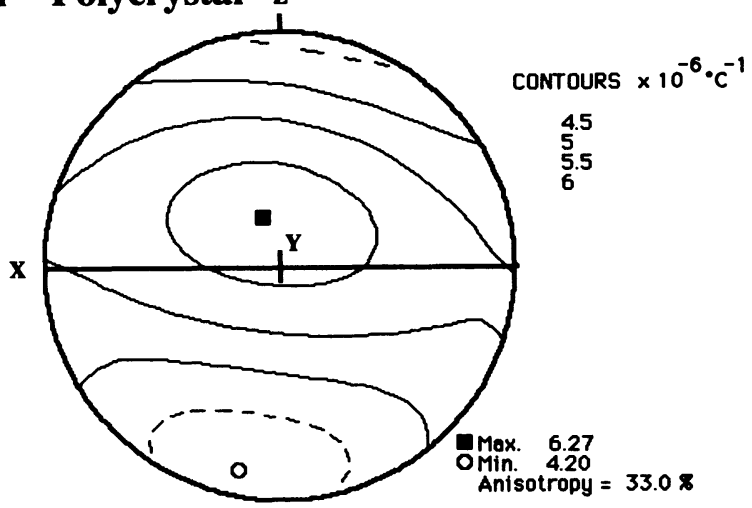

Figure 7 Thermal expansion of single crystal (An 76) and polycrystalline anorthosite for the temperature range $0-600^{\circ} \mathrm{C}$. Note the hyperboloid distribution of the single crystal contours.

where

$$
S_{1111}^{\prime}=X_{m} \cdot X_{n} \cdot X_{o} \cdot X_{p} \cdot S_{m n o p}
$$

The calculated variation of Young's modulus with direction in a single crystal of composition An 57 and the Oman anorthite polycrystal are shown in Figure 8. The Young's modulus of the single crystal shows a mirror symmetry about the (010) plane which is due to monoclinic symmetry imposed by the data reduction procedure used to calculate the single crystal elastic constants by Alexandrov et al., 1974. The Albite twinning present in the sample will result in a similar distribution. The anisotropy of the single crystal is extremely strong at $58.5 \%$. The polycrystal has a maximum value of Young's modulus in the $Z$ sample direction (Figure 8), which correlates with the strong concentration of $(010)$ poles (Figure 2). The minimum Young's modulus value is close to the $\mathrm{Y}$ specimen 


\section{YOUNG'S MODULUS}

Single Crystal - An57

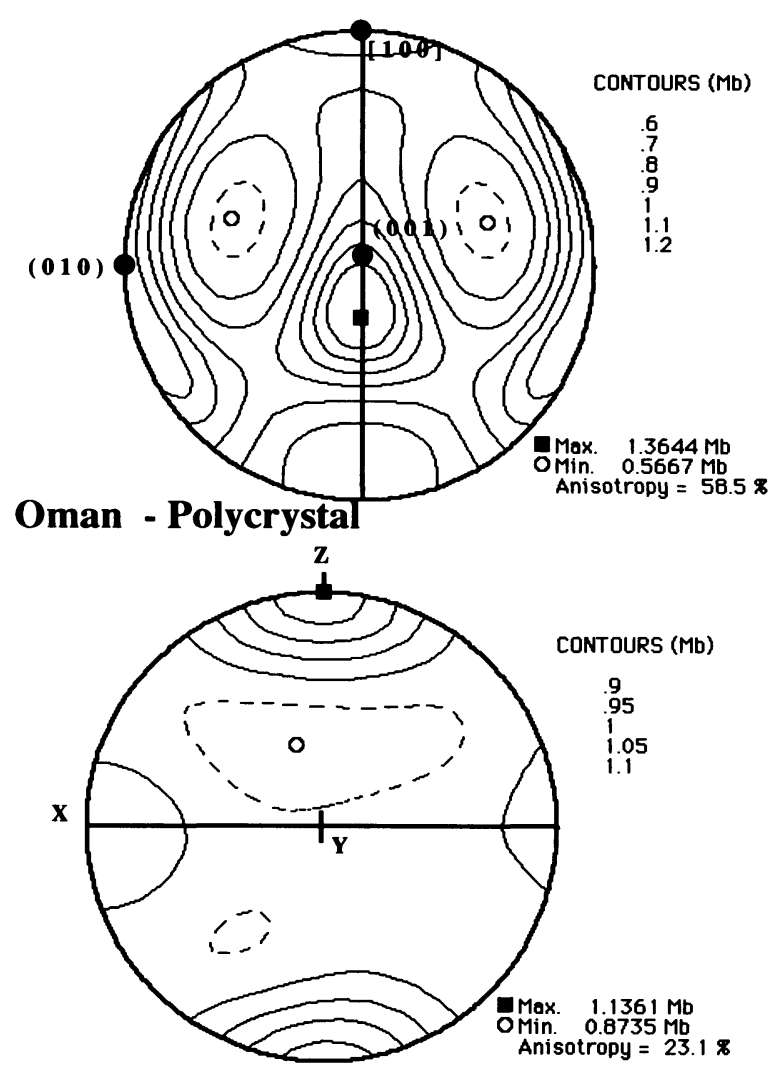

Figure 8 Young's modulus for single crystal (An 57) and polycrystalline anorthosite. Note the mirror symmetry of the single crystal properties.

direction and almost in an identical orientation to the maximum value of the thermal expansion (Figure 7).

Many ceramics and geological materials are brittle at temperatures less than half of the melting temperature. Such insulating materials are very anisotropic in the physical and materials properties. We have seen above that the calculated thermal expansion and Young's modulus of the plagioclase polycrystal have aniostropies of 33 and $23 \%$ respectively. Under conditions of temperature increase or decrease we can expect the anisotropies of thermal expansion and elastic properties to result in high thermal stresses and cracking at low to moderate temperatures. We can estimate an upper bound to the thermal stresses $(\sigma)$ in a direction $X_{i}$ by using the following relationship,

$$
\sigma=\alpha \cdot E \cdot \Delta T
$$




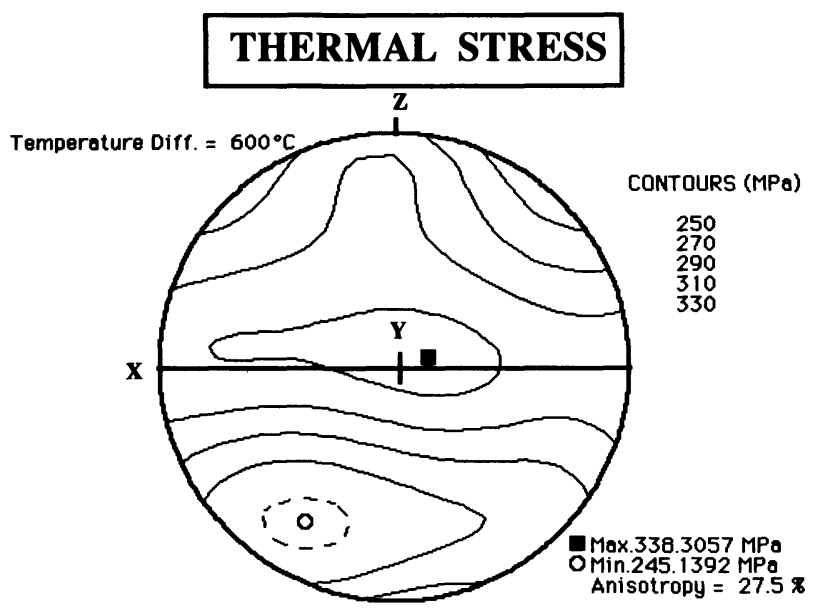

Figure 9 The thermal stress in the polycrystalline anorthosite calculated for a temperature change of $600^{\circ} \mathrm{C}$ using the thermal expansion given in Figure 7 and the Young's modulus given in Figure 8.

where $\alpha$ is the thermal expansion, $E$ is the Young's modulus and $\Delta T$ is the temperature change. The relationship is only strictly valid if the specimen is rigidly constrained in the direction $X_{i}$ (Davidge, 1979). In general the thermal stresses will be lower as the surrounding materials are not perfectly rigid, although in the case of geological materials at depth in the Earth there is a hydrostatic pressure opposing the expansion. Using the above relationship, a temperature difference of $600^{\circ} \mathrm{C}$, the thermal expansion and Young's modulus distribution given in Figures 7 and 8 we have calculated the variation of thermal stress with direction in the plagioclase polycrystal (Figure 9). Thermal stresses of over $300 \mathrm{MPa}$ are predicted in the XY (foliation) plane. In the case of a cooling igneous body, such as the Oman anorthosite, the stresses will be tensile. Ceramics and geological materials are extremely weak in tension, the preferred fail mode is usually by tensile mode I cracking (Atkinson, 1984). In the present example, if we assume mode I failures, then pole to fracture plane figure should have the same distribution to the thermal stress given in Figure 9.

\section{CONCLUSIONS}

Quantitative texture analysis has been applied to a plagioclase polycrystal (anorthosite) with triclinic crystal and specimen symmetries. Strong texture components were measured with intensities of over 20 times a uniform distribution in the ODF. The texture components could be classified into two groups with group I showing an axial distribution and group II a much less marked axial character. The (001) pole in group I coincided with the axis of revolution in specimen co-ordinates parallel to the specimen $\mathrm{Z}$ axis (pole to the foliation). The ODF has been used to calculate the thermal expansion, Young's modulus and thermal stresses of the plagioclase polycrystal. It is suggested that the thermal stress distribution can be used to estimate the distribution of thermally induced tensile (mode I) cracks. 


\title{
ACKNOWLEDGMENTS
}

\author{
The authors thank the CNRS/INSU DBT-Instabilities program for financial \\ support.
}

\section{References}

Aleksandrov, K. S., Alchikov, U. V., Belikov, B. P., Zaslavskii, B. I. and Krupnyi, A. I. (1974). Velocities of elastic waves in minerals at atmospheric pressure and increasing precision of elastic constants by means of EVM (in Russian), Izv. Acad. Sci. USSR, Geol. Ser., 10, 15-24.

Allard, B. and Benn, K. (1989). Shape preferred orientation analysis using digitized images on a microcomputer, Computer and Geosciences, 15, 441-448.

Atkinson, B. K. (1984). Subcritical crack growth in geological materials, J. Geophys. Res., 89, 4077-4114.

Benn, K. and Mainprice, D. (1989). An interactive program for determination of plagioclase crystal axes orientations from U-stage measurements: an aid for petrofabric studies, Computers and Geosciences, 15, 1127-1142.

Bunge, H. J. (1982). Texture Analysis in Materials Science, Butterworths, London.

Davidge, R. W. (1979). Mechanical Behaviour of Ceramics, Cambridge University Press, Cambridge.

Friedrich, J. T. and Wong, T.-F., 1986. Micromechanics of thermally induced cracking in three crustal rocks, J. Geophys. Res., 91, 12743-12764.

Harvey, P. K. and Laxton, R. R. (1980). The estimation of finite strain from the orientation distribution of passively deformed linear markers: eigenvalue relationships, Tectonophysics, 70, 285-307.

Kruhl, J. H. (1987). Preferred lattice orientations of plagioclase from amphibolite and greenschist facies rocks near the insubric line (Western Alps), Tectonophysics, 135, 233-242.

Nicolas, A., Reuber, I. and Benn, K. (1988). A new magma chamber model based on structural studies in the Iman ophiolite, Tectonophysics, 151, 87-105.

Schmid, S. M. and Casey, M. (1986). Complete fabric analysis of some commonly observed quartz c-axis patterns, in Paterson Volume, pp. 263-286, Ed. Heard, H. C. and Hobbs, B. E., AGU monograph, Washington D.C.

Seront, B., Mainprice, D. and Christensen, N. I., in press. A determination of the 3-dimensional seismic properties of anorthosite-comparison between values calculated from the petrofabric and direct laboratory measurement, J. Geophys. Res.

Wagner, F., Wenk, H. R., Esling, C. and Bunge, H. J. (1981). Importance of odd coefficients in texture calculation for trigonal-triclinic symmetries, Phys. Status Solid., A67, 269-285.

Wenk, H.-R., Wagner, F., Esling, C. and Bunge, H. J. (1981). Texture representation of deformed dolomite rocks, Tectonophysics, 78, 119-138.

Wenk, H.-R. and Wilde, W. R. (1972). Orientation distribution diagrams for three Yule marble fabrics, in Flow and Fracture of Rocks, pp. Ed. Heard, H. C., Borg, I. Y., Carter, N. L. and Raleigh, C. B., Am. Geophys. Union, Washington D.C.

Wenk, H. R. (1985). Carbonates, in: Preferred Orientation in Deformed Metals and Rocks, pp. 507-525, Ed. H. R. W., Academic Press, Orlando.

Wenk, H. R., Bunge, H. J., Jansen, E. and Pannetier, J. (1986). Preferred orientation of plagioclase-neutron diffraction and U-stage data, Tectonophysics, 126, 271-284.

Williame, C., Brown, W. L. and Perucaud, M. C. (1974). On the Orientation of the Thermal and Compositional Strain Ellipsoids in Feldspars, Am. Mineral., 59, 457-464. 